\title{
Identifying Optimal Friction Stir Welding Process Parameters for 2024 Al Alloy Butt Joints
}

\author{
Rafał Kluz ${ }^{*}$, Magdalena Bucior ${ }^{1}$, Andrzej Kubit ${ }^{1}$ \\ 1 Rzeszow University of Technology, Faculty of Mechanical Engineering and Aeronautics, al. Powstańców \\ Warszawy 8, 35-959 Rzeszów, Poland \\ * Corresponding author's e-mail: rkktmiop@prz.edu.pl
}

\begin{abstract}
Friction stir welding (FSW) is a solid state joining process used to join metals and their alloys. The main goal of this paper was to select the optimal welding parameters such as: rotational speed and the feed rate of the tool. The article presents the results of the tests on welding $1 \mathrm{~mm}$ thick 2024 aluminum sheet according to the statistical 3-level completed plan PS/DK 32. The rotational speed of the tool varied within the range of 1100-1300 rpm and the feed rate within the range of $40-60 \mathrm{~mm} / \mathrm{min}$. For these parameters, the analyses of the experiment repeatability, impact significance and adequacy of equations were conducted.
\end{abstract}

Keywords: design of an experiment, friction stir welding, aluminum alloy.

\section{INTRODUCTION}

Friction stir welding is one the most modern methods of joining metals and their alloys in the solid state. It was developed and patented in 1991 by The Welding Institute (TWI Ltd) [1]. Since then, its dynamic development has been observed, especially in the United States and Japan, where it has found its first industrial application in railway and aerospace industry. It is particularly useful for joining materials which are difficult to weld using traditional technology, such as steel and highly durable aluminum, copper and titanium alloys, as well as some nickel, zirconium and copper alloys, etc. $[1,2]$.

This method of heating and plasticising the material uses a rotating cylindrical tool put in the place of joining the clamped sheets. After setting the tool in rotation, heating the sheet material by the heat extracted in the process of friction and its plasticising, the whole unit is gradually traversed along the joint line (Fig. 1 ). The heated and plasticised sheet material is compressed by the tool shoulder before being cooled down $[3,4]$.
Friction Stir Welding is a method for welding in a solid state, below the melting temperature of the joined material. Using this method, the obtained mechanical properties of the joints can be higher than when a welding technology is used. An additional advantage is the elimination of expensive protections against harmful smokes and liquid metal spatters. In addition, the possibilities of joining the elements made of aluminum alloy gives the possibility to use this method in the production of aerospace structures while reducing labour, costs and their weight, and retaining comparable or higher mechanical parameters compared to traditional methods $[5 \div 9]$.

However, ensuring the repeatability of the operating parameters of joints requires an optimal choice of the welding process parameters, out of which the most important ones are: tool rotational speed, feed rate, tool inclination angle, pressure and plunge depth (Fig. 1). The aim of the work was to determine the influence of these parameters on the selected properties of the joints made with FSW, and the development of a mathematical model which ensures selecting optimal parameters. 


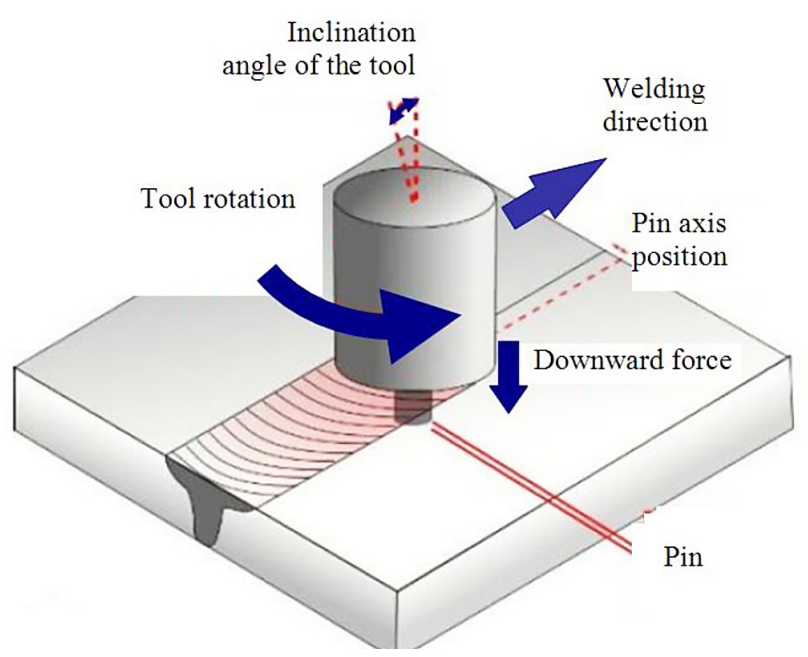

Fig. 1. Schematic of friction stir welding [2]

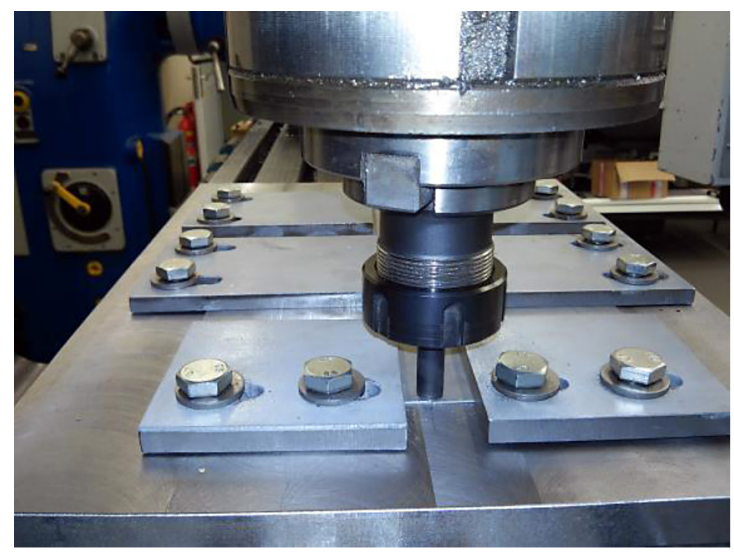

Fig. 2. Friction stir welding stand

\section{EXPERIMENTAL STUDIES}

The studies on the stand and unique position of the edges of the joined sheet in relation to the tool were carried out (Fig. 2).

The initial studies show that the welding process is influenced the most by: table feed rate of a milling table $v_{f}$, tool rotational speed $n$ and the inclination angle of the tool. Other parameters do not have a significant impact on the quality of the weld. In order to obtain reliable information from the tests carried out with a minimum effort, a study was made on the basis of the statistical 3-level completed test plan PS/DK 32. The input factors appear on three levels in this plan [5]:

- Higher - marked with +1 ,

- medium (zero) - marked as 0 ,

- lower-marked with -1.

The studies were conducted for two different tool inclination angles $\left(2^{\circ}\right.$ and $\left.3^{\circ}\right)$. Mechanical studies included a static test of tension, on the basis of which the maximum power transmitted by the joint was recorded. The samples for the mechanical tests were removed from sheet stripes joined by FSW in a direction perpendicular to the joint line. The width of the samples was $12.5 \mathrm{~mm}$.

On the basis of the studies [6, 7], the parameters for the welding process were pre-established: feed rate of $70 \mathrm{~mm} / \mathrm{min}$, and the tool rotational speed of $1120 \mathrm{rpm}$. With these parameters, one of the higher values of the joint effective power was recorded. However, a large variance of the obtained measurement results prevented obtaining an adequate regression model. In order to obtain the correct model in the studies, the focus was put on the lower feed rate values $(40-60 \mathrm{~mm} / \mathrm{min})$ and rotational speed (1100-1300 rpm) at which a significantly smaller dispersion of measurement results with a slightly lower value of the power transmitted by the joint was observed.

At the inclination angle of the tools amounting to $2^{\circ}$, the largest value of the breaking force (4.75 $\mathrm{kN}$ ) was obtained for the samples made with the ro- 
tational speed of $1200 \mathrm{rpm}$ and the feed rate equal to $40 \mathrm{~mm} / \mathrm{min}$. Increasing the tool inclination angle to $3^{\circ}$ enabled to obtain the maximum breaking force of $4.85 \mathrm{kN}$ at the rotational speed of $1300 \mathrm{rpm}$ and the feed rate of $50 \mathrm{~mm} / \mathrm{min}$. These values consist in $83.3-85.1 \%$ of the force required to break the samples taken from the whole base material $(5.7 \mathrm{kN})$.

The analysis of the breaking force $\mathrm{F}$ graph in a function of the feed rate for both samples made at the tool inclination angle of $2^{\circ}$ (Fig. 3) and $3^{\circ}$ (Fig. 4) indicates a non-linear nature of the impact of changing the feed rate on the value of the force transmitted by the weld. In the case of the samples made at the tool inclination angle of $2^{\circ}$, the similarity between the curves obtained for the rotational speed of $1100 \mathrm{rpm}$ and $1200 \mathrm{rpm}$ may be noticed.

Both curves show the initial upward tendency in strength, together with the increase of the feed rate, followed by a moderate decline in the joint strength. Additionally, this decline is more noticeable for the samples made with the rotational speed equal to $1100 \mathrm{rpm}$. For the samples made with the rotational speed of $1300 \mathrm{rpm}$, the decline

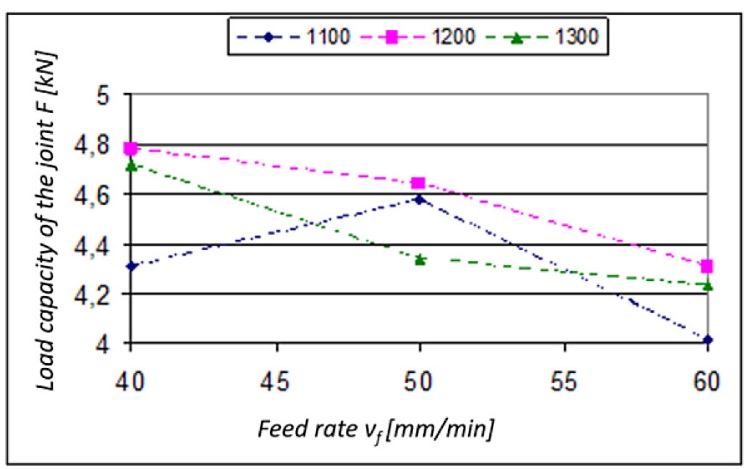

Fig. 3. The relation between the maximum force $\mathrm{F}$ transferred by the joint and the feed rate $\left(\gamma=2^{\circ}\right)$

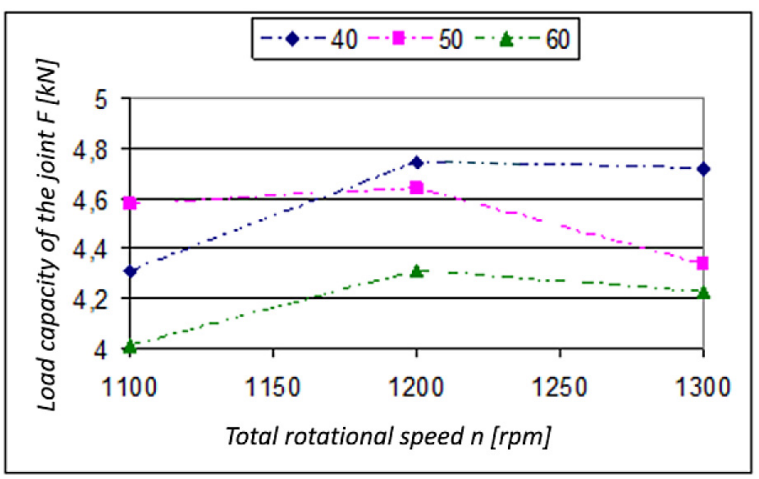

Fig. 5. The relation between the maximum force $F$ transferred by the joint in the function of the spindle rotational speed change $\left(\gamma=2^{\circ}\right)$ in the joint load capacity, together with the increase of the feed rate may be observed.

In the case of the samples taken at the angle of the tool inclination of $3^{\circ}$, regardless of the used tool rotational speed, the largest joint load capacity may be achieved at the feed rate of $50 \mathrm{~mm} /$ mim. A further increase in the feed rate resulted in the reduction of the joint strength.

By analyzing the graphs of the relation between the maximum force transferred by the joint in the function of the rotational speed change, it may be noticed that the curves assigned to the appropriate feed rates show a similar tendency, regardless of the adopted tool inclination angle.

In the case of the samples made at the angle of the tool inclination angle of $2^{\circ}$ (Fig. 5), regardless of the adopted tool feed rate, the highest joint strength was observed for the rotational speed of $1200 \mathrm{rpm}$. All the characteristics are non-linear and they approximately reflect the tendency of the joint strength to decrease along with a further increase in the rotational speed of the spindle. The largest increase in the weld strength $(+10.2 \%)$ was observed for the samples made with the feed rate of $40 \mathrm{~mm} / \mathrm{min}$ af-

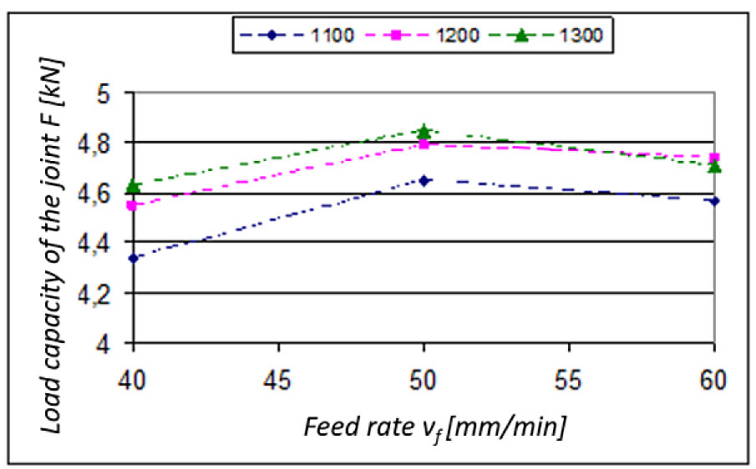

Fig. 4. The relation between the maximum force $\mathrm{F}$ transferred by the joint and the feed rate $\left(\gamma=3^{\circ}\right)$

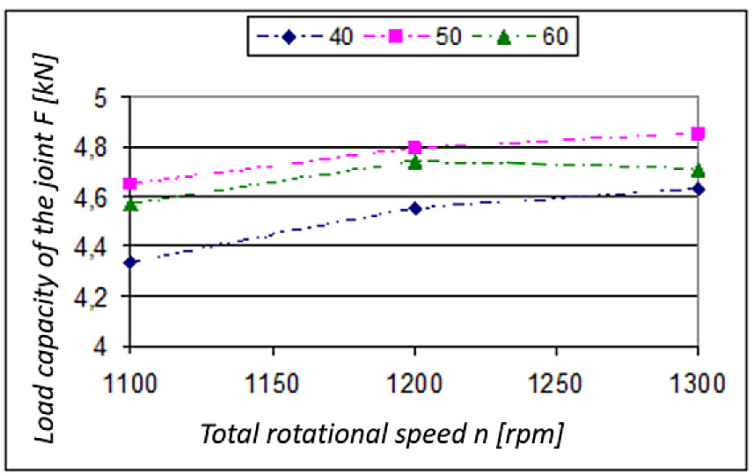

Fig. 6. The relation between the maximum force $F$ transferred by the joint in the function of the spindle rotational speed change $\left(\gamma=3^{\circ}\right)$ 
ter increasing the rotational speed from $1100 \mathrm{rpm}$ to $1200 \mathrm{rpm}$ achieving the load capacity of $4.75 \mathrm{kN}$.

At the angle of the tool inclination of $3^{\circ}$ (Fig. 6), the largest joint load capacity was observed for the samples taken at the rotational speed of $1300 \mathrm{rpm}$. In each of the analysed examples, the increase of the rotational speed resulted in the increase of the joint load capacity, and the highest enhancement was observed along with the rise of the speed from 1100 to $1200 \mathrm{rpm}$. A further increase in the speed caused a slight improvement in the joint load capacity, and even a small decrease in the case of the feed rate of $60 \mathrm{~mm} / \mathrm{min}$.

However, the attention should be paid on the fact that this type of a comparative analysis is insufficient to assess the overall impact of the changes in the process parameters on the quality of the formed weld. The correct analysis requires the development of a mathematical model.

\section{MATHEMATICAL MODEL}

The goal of the research was to develop an adequate mathematical model in the form of the second degree polynomial with a significance level of $\alpha=0.05$ :

$$
y=b_{o}+\sum b_{k} x_{k}+\sum b_{k k} x_{k}^{2}+\sum b_{k j} x_{k} x_{j}
$$

where: $x_{k}, x_{j}$ - input factors, $b_{o}, b_{k}, b_{k k}, b_{k j}-$ regression equation coefficients, $y$-output factor (a measured value).

The repeatability rating (stability) of the conditions for conducting the experiment was made with the use of Cochran criteria. In order to verify the hypothesis of the variance repeatability, a $G$ coefficient was determined:

$$
G=\frac{S^{2}(y)_{i \max }}{\sum_{i=1}^{N} S^{2}(y)}
$$

It was compared to the critical value based on the accepted significance level of $\alpha=0.05$ and the number of the degrees of freedom determined on the basis of the relationship:

$$
\begin{gathered}
f_{1}=N=9 \\
f_{2}=r-1=2
\end{gathered}
$$

where $r$-is the number of parallel measurements.

The value of Cochran's statistics was lesser than the critical value $G_{k r}$. As a result, the repeatability of the experimental conditions can be considered satisfactory. The factor significance rating of the regression equation was conducted by comparing its values with the critical value determined with the formula:

$$
b_{k r}=t_{(\alpha, f)} \sqrt{\frac{S^{2}(y)}{N r}}
$$

where $t_{(\alpha, f)}$ is the test value of the $t$ coefficient from the t-Student chart.

Considering the absolute value of all the regression equation coefficients, it was greater than the critical value $\left|b_{k}\right|>b_{k r}$. It was accepted that they affected the regression function value significantly.

In order to determine how adequate the regression equation is, a Fisher-Snedecor test was used. During the first stage of the analysis, the adequateness variance was determined:

$$
S_{a d}^{2}=\frac{r \sum_{i=1}^{N}\left(\overline{y_{i}}-\overline{y_{i}}\right)^{2}}{N-k-1}
$$

where: $\bar{y}_{i}-$ is an average value of the measurement results in the $i^{\text {th }}$ experiment, $\overline{\bar{y}}_{i}-$ is the value calculated from the regression equation for the input and output factors of the $i^{\text {th }}$ experiment, $k$-is the number of regression equation expressions (without a free expression) after rejecting insignificant expressions, $r$-is the number of repetitions, $N-$ is the number of experiments.

Next, the value of the F test coefficient was determined:

$$
F=\frac{S_{a d}^{2}(y)}{S^{2}(y)}
$$

It was compared to the critical value from the Fisher-Snedecor distribution obtaining adequate regression equations that describe the impact of the friction stir welding on the joint load capacity of the following:

$$
\begin{aligned}
y_{F} & =-22.4355+0.3703 n-0.0000146 n^{2} \\
& +0.192 v_{f}-0.00186 v_{f}^{2}-0.00002 n v_{f}
\end{aligned}
$$

for the joints made at the angle of the tool inclination angle of $2^{\circ}$ (Fig. 7) and:

$$
\begin{aligned}
& y_{F}=-11.861+0.0168 n-5.33 \cdot 10^{-6} n^{2} \\
& +0.2315 v_{f}-0.001433 v_{f}^{2}-0.0000649 n v_{f}
\end{aligned}
$$

for the joints made at the angle of $3^{\circ}$ (Fig. 8).

Figures 7 and 8 show the graph of the relation of the maximum force transferred by the joint, and the feed rate and the tool rotational speed. In the case of the joints made at the angle of the tool inclination of $2^{\circ}$, the highest load capacity (4.68 $\mathrm{kN}$ ) may be achieved at the rotational speed of 


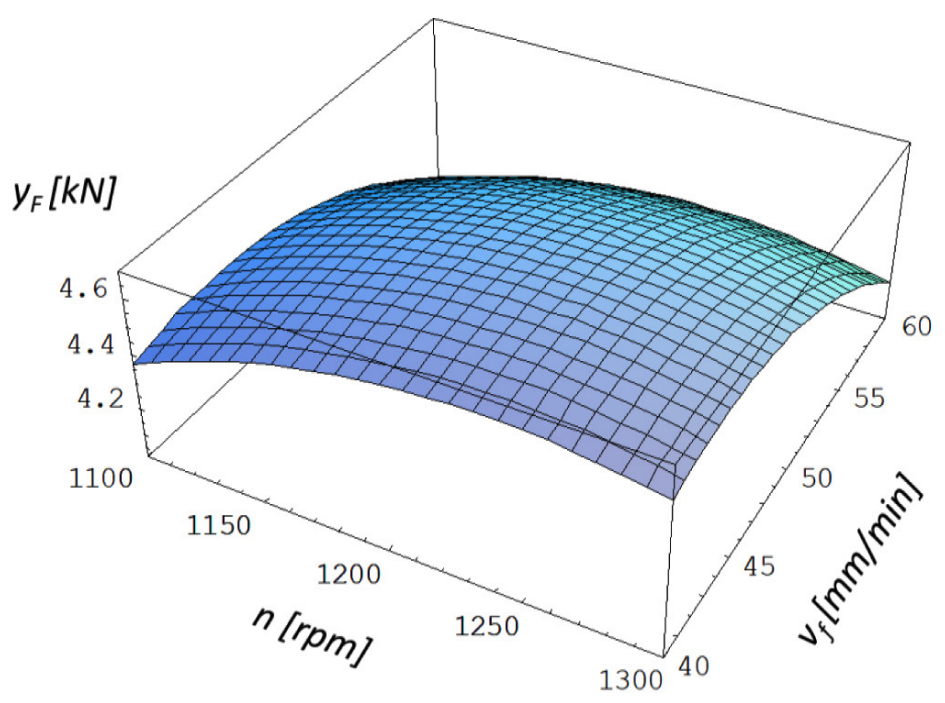

Fig. 7. The graph of the relation of the joint load capacity and the rotational speed and feed rate $\left(\gamma=2^{\circ}\right)$

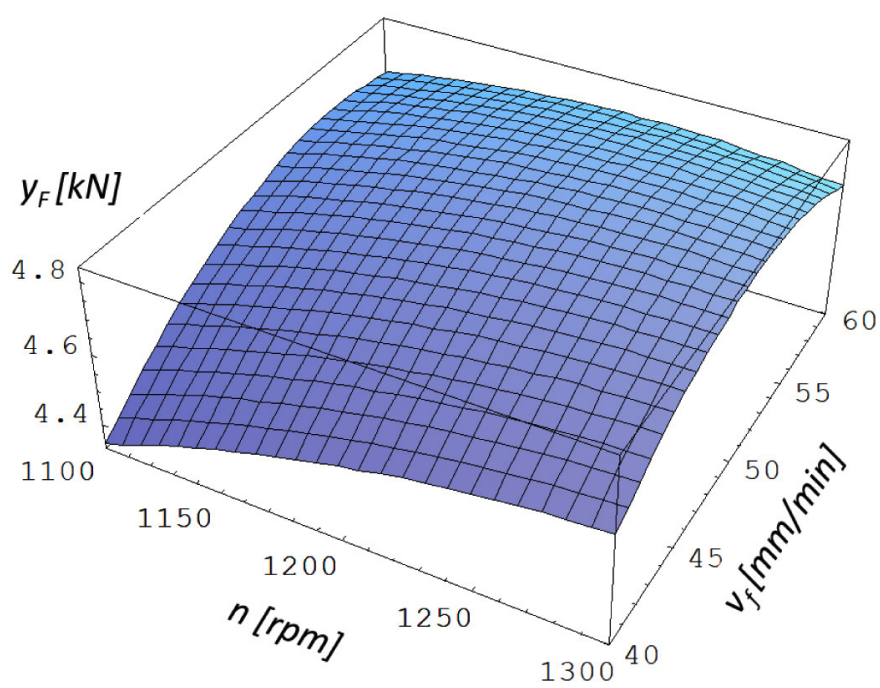

Fig. 8. The graph of the relation of the joint load capacity and the rotational speed and feed rate $\left(\gamma=3^{\circ}\right)$

$1230 \mathrm{rpm}$ and the feed rate of $45 \mathrm{~mm} / \mathrm{min}$. After increasing the angle of the tool inclination to $3^{\circ}$, the joint load capacity of $4.85 \mathrm{kN}$ may be obtained at the speed of $1265 \mathrm{rpm}$ and feed rate of $52 \mathrm{~mm} / \mathrm{rpm}$. The graph analysis also points to the existing provisions concerning the ability to increase the joint stability by modifying the process setup parameters (the inclination angle of a tool). However, it requires additional studies.

\section{CONCLUSION}

Friction Stir Welding is one of the most attractive methods of joining crucial construction elements in the aerospace and automotive industries, due to its tightness and high stability of joints as well as the possibility of reducing its weight. The studies on friction stir welding showed that this method can be used for joining sheets of aluminum alloy 2024 with a thickness of $1 \mathrm{~mm}$. The conducted studies indicated that the highest load capacity at the tool inclination angle of $2^{\circ}$ can be obtained for the rotational speed $1230 \mathrm{rpm}$ and the feed rate of $45 \mathrm{~mm} / \mathrm{min}$, and at the tool inclination angle of $2{ }^{\circ}$ with the rotational speed of 1265 $\mathrm{rpm}$ and the feed rate of $52 \mathrm{~mm} / \mathrm{min}$. However, it should be noted that with the tool inclination angle of $3^{\circ}$ the weld of the more even front and root was obtained, than in the case of a smaller angle of the tool inclination, which may be reflected in the fatigue strength of this type of joints. 


\section{REFERENCES}

1. Ahmed M.M.Z., Ataya S., El-Sayed Seleman M.M., Ammar H.R., Ahmed E. Friction stir welding of similar and dissimilar AA7075 and AA5083. Journal of Materials Processing Technol., 242, 2017, 77-91.

2. Balos S., Sidjanin L., Dramicanin M., Zlatanovic D.L., Antic A. FSW welding of Al-Mg alloy plates with increased edge roughness using square pi tools of various shoulder geometries. Mater. Tehnol., 50, 2016, 387-394.

3. Hattingh D.G., Blignault C., Niekerk T.I., James M.N. Characterization of the influences of FSW tool geometry on welding forces and weld tensile strength using an instrumented tool. Journal of Materials Processing Technol. 203, 2008, 46-57.

4. Korzyński M.: The experiment methodology, WNT, Warsaw 2006.
5. Mishra R.S., Friction Stir Processing Technologies. Advanced Materials \& Processes, October 2003.

6. Sadeesh P., Kannan M.V., Rajkumar V., Avinash P., Arivazhagan N., Ramkumar K.D., Narayanan S., Studies on friction stir welding of AA 2024 and AA 6061 dissimilar metals. Procedia Engineering, 75, 2014, 145-149.

7. Sidhar H, Martinez N.Y., Mishra R.S. Friction stir welding of Al-Mg-Li 1424 alloy. Materials \& Design, 106 ,2016, 146-152.

8. Su H., Wu C.S., Pittner A., Rethmeier M. Thermal energy generation and distribution in friction stir welding of aluminum alloys. Energy, 77, 2014, 720-731.

9. Tang J., Shen Y., Numerical simulation and experimental investigation of friction stir lap welding between aluminum alloys AA2024 and AA7075. Journal of Alloys and Compounds, 666, 2016, 493-500. 